\title{
Revised health and safety compliance model for the Ghanaian construction industry
}

\author{
Zakari Mustapha \\ Department of Building Technology, School of Engineering, P.O. Box AD. 50, Cape Coast Polytechnic, Cape Coast, GHANA \\ "Author's e-mail: zakari.mustapha1967@gmail.com
}

\begin{abstract}
The construction industry in Ghana is faced with employees' negligence in obeying rules and regulations, and acts that conflict with health and safety. The purpose of the paper was to present the revised health and safety (H\&S) compliance model for the construction industry based on a developed theoretical six factor model. Exploratory Factor Analysis (EFA) was conducted on the theoretical model to assess whether the variables were suitable for Confirmatory Factor Analysis (CFA).The EFA carried out on the theoretical model led to the revision of the H\&S compliance model. The extraction method employed on the theoretical six factor model during the EFA was Principal Axis Factoring with Oblimin Rotation (PAF Oblimin).Findings from the study show that Total Variance Explained had fourteen factors above 1.00. Further findings show that four factors were retained from the six factor theoretical model. In some cases few variables were combined with other factors to form new factors. The combination of the variables led to the formation of new factors with different latent constructs. The remaining two factors from the theoretical model also form part of the new constructs. Twelve factors were finally obtained from the EFA, with a minimum of three variables each. The factors with negative factor loadings indicate their weakness in the model because they cross load over another. Hence, two factors with highest number of negative factor loadings were dropped, remaining ten factors with good communalities above 0.3 as shown in the revised model.
\end{abstract}

Keywords: Compliance, exploratory factor analysis, Ghana, health and safety, model

DOI: http://dx.doi.org/10.4314/ijest.v8i2.4

\section{Introduction}

The theoretical conceptual model has been revised as shown in Figure 2 (Model 2.0) after an EFA was conducted on the theoretical six factor latent constructs as shown in Figure 1 (Model 1.0). The theoretical H\&S compliance model is based on literature and the views from experts' in the Delphi Study. Mustapha et al.(2015) in their study of conceptualized integrated H\&S compliance model for the Ghanaian construction industry concluded that the developed model will serve as a guide to project managers. They further emphasized on reduction of accidents and increase in productivity. This indicates the need for the development of the H\&S compliance model to assist in the elevation of the existing OHS challenges. Annan et al. (2015) posited that the challenges were due to the existence of some fragments of OHS legal requirements under jurisdictions of different agencies. A study by Mustapha et al. (2015) on the examination of safety performance regulations concluded that the exclusion of the International Labour Organization (ILO) convention number 155 in Ghana is a major factor. Mustapha et al., (2015) further emphasised on the need for the structuring of the OHS policies in Ghana and all government officials must be involved and committed. The OHS policy to be adopted or developed by Ghana should follow ILO convention as a minimum requirement. The paper discussed OHS Challenges in Ghana and OHS Improvement in Ghana. 


\section{Methodology}

The methodology section gives a detail of the methodology used to arrive at the revised model for health and safety compliance for the Ghanaian construction industry. The theoretical or the six factor model was developed based on information from literature review and Delphi survey results.Both qualitative and quantitative methods of data collection were employed in the study. A Delphi survey was conducted for the qualitative aspect of the study and a field survey was used for the quantitative aspect. Nine experts (academics and construction professionals) were involved in the Delphi survey. A face-to-face method of questionnaire administration was adopted for the quantitative aspect of the study. Data gathered via a questionnaire survey were analysed using Structural Equation Modeling (SEM) software 20. The SPSS was used to evaluate the reliability, discriminant validity and convergent validity of the instrument (Pallant, 2007; Leedy and Ormrod, 2010).PAF Oblimin was used as an extraction method for the elements. Structural Equation Modeling (SEM) process was undertaken as EFA for analysis of the theoretical conceptual model elements. The SEM software was used to assess the factor structure of the constructs of the theoretical model or the six factor model in Figure 1 (Model 1.0).The sample size of 557 obtained for the current study is considered as large (Kline, 2005, (Bentler and Chou, 1987; Bollen, 1989). This falls within the acceptable value for SEM to be conducted (Harris and Schaubroeck, 1990; Kline, 2005). MacCallum, Browne, Sugawara (1996); Tong (2007) emphasised on an appropriate sample size which depend on observed variables. The variable ratio to sample size for the current study is 8.44:1 (Tong, 2007). The theoretical conceptual model elements was analysed using EFA. PAF Oblimin was used to determine the unidimensionality of the elements. Bartlett's Test of Sphericity and the Kaiser-Meyer- Olklin (KMO) was also used to measure the accuracy of the sample (Farrington, 2009; Hair et al., 2010).

\section{Occupation Health and Safety Challenges in Ghana}

This section provides information in literature in relation to Occupational Health and Safety (OHS)challenges in Ghana. The preceding sections 4 and 5 which form part of the literature provide improvement strategy in addition to a brief content on International Labour Organization (ILO) convention, 1981 (No. 155).The inability of the Ghanaian government to ratify the ILO convention, 1981 (No. 155) has contributed to the OHS challenges in Ghana. This development has affected the construction industry as indicated by Annan et al. (2015). Kheni et al. (2008) identified inadequate government support for regulatory institutions and lack of skilled human resources. Dadzie (2013) also identified H\&S training deficiency, inability to assess danger and workers reluctant attitudes towards H\&S. Human resources development and inadequate OHS capacity for the industry has been indicated as some of the challenges (Puplampu and Quartey, 2012). Even though, the concept of OHS in industries was conceived in Ghana before the introduction two major edicts (Annan et al., 2015). The existence of some fragments of OHS legal requirements under jurisdictions of different agencies in Ghana has led to the OHS challenges in Ghana (Annan et al., 2015).

\section{Occupational Health and Safety Improvement in Ghana}

There are several regulatory bodies in Ghana. The existence of several regulatory bodies in Ghana have compounded the OHS challenges (Annan et al., 2015): (i) Mining and Minerals Regulations 1970 LI 665, (ii) The Workman's Compensation Law 1987, (iii) The Ghana Health Services and Teaching Hospital Act 526 (1999), (iv) The Ghana Labour Act 2003 (Act 651), (v) The Radiation Protection Instrument LI 1559 of 1993, (vi) The Environmental Protection Agency Act 1994 (Act 490), and (vii) The National Road Safety Commission Act 1999 (Act 567). However, the OHS activities depend solely on the Factories, Offices, and Shops Act 1970 (Act 328) and the Mining Regulations 1970 LI 665 which have limited scope considering the number of industrial activities. The OHS challenges can be improved upon by ratifying the ILO convention, 1981 (No. 155).

\section{International Labour Convention 1981 (No. 155)}

The ILO convention, 1981 (No. 115) is important due to some fundamental ideas and ways of carrying out activities put in place for OHS management improvement. It introduces interrelated activities of a national policy to OHS. The national OSH policy gives a framework to reduce hazards at workplace and this should be formulated, implemented and reviewed yearly. Articles 7 of the Convention indicates that the formulation, implementation and yearly review of the national OSH policy should be done through identification of major problems and provide methods that are effective. Since the aim of the policy under Article 4.2 of Convention No. 155 is prevention of accident and injury at workplace. Hence, the national OSH policy activities should be towards OHS improvement (Building a Preventative Safety and Health Culture, 2013). Figure 1 (Model 1.0) was developed based on literature review information and Delphi survey results as discussed under the introduction section.

\section{Measurement Components of the theoretical model or the six factor model}

The measurement components of the model in this section provides information on the number of latent constructs or variables for each of the factors under discussion.Figure 1 shows that Safe Environment (SE) with six latent constructs or variables, Safe Acts of Workers (SAW) with twenty latent constructs or variables, Safe Work Condition (SWC) with seven latent constructs or 
variables, Reaction of Workers to Safe Condition (RWSC) with five latent constructs or variables, Government Support (GS) with five latent constructs or variables and Contractors' Organisational Culture (COC) with eleven latent constructs or variables. While Health and Safety Compliance (HSC) has seven latent constructs or variables.

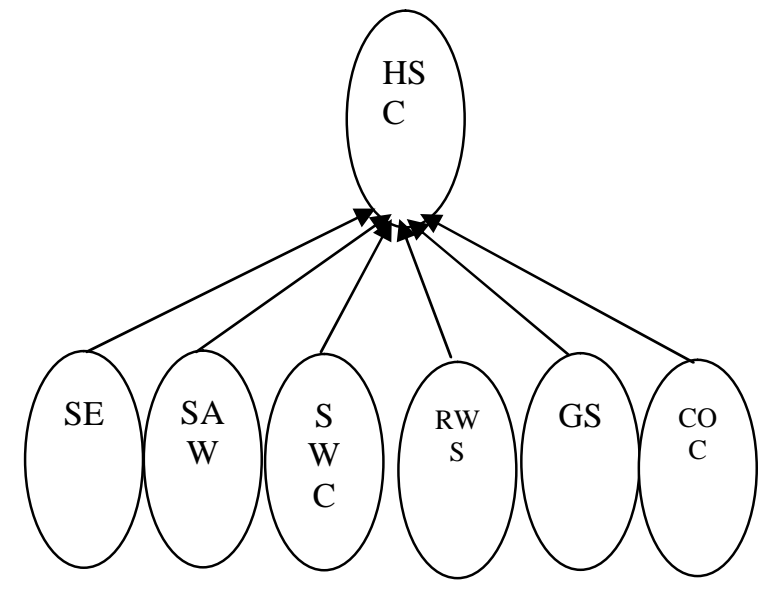

Figure 1: Conceptual health and safety (H\&S) compliance model (Model 1.0)

\section{Findings and Discussion of Results}

The finding section provides detail information on how the revised model was achieved. At the end of the EFA on the theoretical H\&S compliance model. Fourteen factors were realized, but two factors have less than three variables. The factors with two elements or variables were removed from the rest of the factors. The final refined H\&S conceptual model comprised of twelve latent constructs (Figure 2). Four of the theoretical H\&S latent constructs names were retained with their measuring indicators. The retained H\&S latent constructs or factors are safe acts of workers (SAW), government support (GS), safe environment (SE) and contractors organisational culture (COC). Eight new elements or leading indicators names were used that is safety of materials and equipment (SME), safety precautions (SP), safety adherence (SA), safety training (ST), facility usage (FU), safe work condition (SWC), workers welfare (WW), and safety regulations (SR). The eight new latent constructs or factors were combination of elements from one latent construct or the other. As indicated earlier, the combination of the new latent constructs or factors was based on the EFA conducted on the theoretical factors of H\&S compliance modelFigure 1(Model 1.0). Kline (2005) indicated that when the construct has few items or indicator variables, less than three, the model will not be over identified for testing, using SEM. The recommended number of items per element was three as shown in Table 2, to enable robust SEM testing (Kline, 2005).

Table 1: Cut-off values of indicators used

\begin{tabular}{|l|l|}
\hline Item-total Correlation & 0.30 \\
\hline Cronbach alpha & 0.70 \\
\hline Kaiser-Meyer- Olklin (KMO) & $\searrow 0.70(p<0.05)$ \\
\hline Bartlett's Test of Sphericity & $p<0.05$ \\
\hline Factor loading & 0.40 \\
\hline
\end{tabular}

Table 2 shows that there were five items each measuring SME and GS. Four items each were measuring SP, AS, ST, FU, SWC, WW, SAW and SE. Only three items were measuring SR and six items were measuring COC. All the variables have factor loadings greater than 0.40, with the exception of AS and FU (Field, 2005; Hair et al., 1998). The two variables with negative values indicate that they cross load over another which make them not suitable for inclusion in the model. The corrected item-total correlation was greater than the suggested cut-off value of 0.30. This implies that the items were good measures of the element. The Cronbach alpha was greater than the cut-off value of 0.70 as pointed out by (Nanually and Bernstein, 1996) to be accepted as an internal reliability.The Kaiser-Meyer-Olkin (KMO) of 0.886 with Bartlett's Test of Sphericity of $p<0.000$ were obtained. These results are in agreement with the recommended KMO cut-off value of 0.70 and Bartlett's Test of Sphericity of $p<0.05$ (Hair et al., 2010).

Table 2: Items measuring each of the variables

\begin{tabular}{|l|l|l|l|l|}
\hline Variable & Question & Factor loading & $\begin{array}{l}\text { Corrected item } \\
\text { total correlation }\end{array}$ & $\begin{array}{l}\text { Cronbach level } \\
\text { after deletion }\end{array}$ \\
\hline SME 1 & Safe storage of formworks and false work & 0.895 & 0.681 & 0.878 \\
\hline SME 2 & Safe transportation of formworks and false work & 0.853 & 0.718 & 0.874 \\
\hline
\end{tabular}


Table 2 (cont'd): Items measuring each of the variables

\begin{tabular}{|c|c|c|c|c|}
\hline Variable & Question & Factor loading & $\begin{array}{l}\text { Corrected item } \\
\text { total correlation }\end{array}$ & $\begin{array}{l}\text { Cronbach level } \\
\text { after deletion }\end{array}$ \\
\hline SME 3 & Safe transportation of materials & 0.726 & 0.713 & 0.874 \\
\hline SME 4 & Do not throw or accidentally drop objects from high levels & 0.531 & 0.549 & 0.881 \\
\hline SME 5 & Ensure proper positioning of tasks & 0.509 & 0.557 & 0.881 \\
\hline SP 1 & Do not smoke in flammable materials store & 0.886 & 0.536 & 0.881 \\
\hline SP 2 & Do not work under the influence of alcohol and other drugs & 0.732 & 0.473 & 0.883 \\
\hline SP 3 & $\begin{array}{l}\text { Ensure equipment /tools are in good condition before } \\
\text { usage }\end{array}$ & 0.517 & 0.490 & 0.883 \\
\hline SP 4 & Use appropriate tools/equipment & 0.426 & 0.522 & 0.882 \\
\hline AS 1 & Adhere to warning signs and notices & -0.768 & 0.662 & 0.817 \\
\hline AS 2 & Follow safety regulations & -0.724 & 0.619 & 0.823 \\
\hline AS 3 & $\begin{array}{l}\text { Adhere to guidance on recommended illumination level for } \\
\text { various tasks }\end{array}$ & -0.610 & 0.556 & 0.830 \\
\hline AS 4 & Adhere to company safety policies & -0.506 & 0.604 & 0.824 \\
\hline ST 1 & Attend safety education programme & 0.758 & 0.609 & 0.823 \\
\hline ST 2 & Attend safety training programme & 0.686 & 0.651 & 0.817 \\
\hline ST 3 & Provision of training & 0.423 & 0.590 & 0.921 \\
\hline ST 4 & Good inspection programme & 0.396 & 0.687 & 0.918 \\
\hline FU 1 & Adhere to regular use of provided change room & -0.691 & 0.486 & 0.840 \\
\hline FU 2 & $\begin{array}{l}\text { Put to proper use of the available facilities (toilet, drinking } \\
\text { water, washing, and canteen) }\end{array}$ & -0.635 & 0.489 & 0.838 \\
\hline FU 3 & Provision of safe means of facilities all the time & -0.446 & 0.651 & 0.919 \\
\hline FU 4 & Provision of change room for workers & -0.416 & 0.627 & 0.878 \\
\hline SWC 1 & Provision of sufficient lighting system for enclosed areas & 0.566 & 0.502 & 0.923 \\
\hline SWC2 & Safe movement around workplace & 0.394 & 0.495 & 0.923 \\
\hline SWC3 & Involve workers in $\mathrm{H} \& \mathrm{~S}$ programme & -0.332 & 0.640 & 0.897 \\
\hline WW 1 & $\begin{array}{l}\text { Provision of break periods for workers to access the } \\
\text { facilities }\end{array}$ & 0.506 & 0.584 & 0.921 \\
\hline WW 2 & $\begin{array}{l}\text { Provision of facilities that are clean, safe and accessible to } \\
\text { all workers }\end{array}$ & 0.453 & 0.730 & 0.918 \\
\hline WW 3 & $\begin{array}{l}\text { Provision adequate facilities ( toilet, drinking water, } \\
\text { washing, and canteen) }\end{array}$ & 0.434 & 0.714 & 0.918 \\
\hline WW 4 & Provision of change room for workers & 0.409 & 0.645 & 0.919 \\
\hline SR 1 & Provide Safety regulations of equipment & 0.592 & 0.531 & 0.922 \\
\hline SR 2 & Provision of Signs/Notices on sites & 0.488 & 0.561 & 0.901 \\
\hline SR 3 & Provision of personal protective equipment (PPE) & 0.414 & 0.598 & 0.899 \\
\hline SAW 7 & Use proper means of lifting, handling or moving of objects & 0.594 & 0.683 & 0.876 \\
\hline SAW 10 & Ensure the use of personal protective equipment (PPE) & 0.577 & 0.527 & 0.881 \\
\hline SAW 8 & $\begin{array}{l}\text { Ensure proper stacking of objects /materials in safe } \\
\text { locations }\end{array}$ & 0.521 & 0.580 & 0.880 \\
\hline SAW 9 & Avoid annoyance and horseplay at the workplace & 0.426 & 0.561 & 0.880 \\
\hline GS 3 & $\begin{array}{l}\text { Monitoring of H\&S policy implementation by the } \\
\text { government representatives }\end{array}$ & 0.960 & 0.865 & 0.896 \\
\hline GS 4 & $\begin{array}{l}\text { Provision of H\&S policy update by government } \\
\text { representatives }\end{array}$ & 0.903 & 0.853 & 0.898 \\
\hline GS 2 & $\begin{array}{l}\text { Implementation of } \mathrm{H} \& \mathrm{~S} \text { policy by government } \\
\text { representatives }\end{array}$ & 0.889 & 0.825 & 0.904 \\
\hline GS 5 & Provision of $\mathrm{H} \& \mathrm{~S}$ training by government representatives & 0.877 & 0.820 & 0.905 \\
\hline GS 1 & Formulate H\&S policy of construction & 0.692 & 0.660 & 0.934 \\
\hline SE 2 & Safe storage of equipment & 0.606 & 0.613 & 0.884 \\
\hline SE 3 & Safe storage of materials & 0.515 & 0.735 & 0.874 \\
\hline SE 7 & Safe transportation of equipment & 0.373 & 0.687 & 0.877 \\
\hline SE 1 & Safe and healthy work environment & 0.337 & 0.667 & 0.0879 \\
\hline COC 9 & Assessment of hazard identification and risk & -0.665 & 0.645 & 0.896 \\
\hline $\operatorname{COC} 8$ & Management commitment in H\&S & -0.605 & 0.703 & 0.893 \\
\hline
\end{tabular}


Table 2 (cont'd): Items measuring each of the variables

\begin{tabular}{|l|l|l|l|l|}
\hline Variable & Question & Factor loading & $\begin{array}{l}\text { Corrected item } \\
\text { total correlation }\end{array}$ & $\begin{array}{l}\text { Cronbach level } \\
\text { after deletion }\end{array}$ \\
\hline COC 11 & Update on H\&S information to workers & -0.541 & 0.643 & 0.896 \\
\hline COC 10 & Communication of H\&S information to workers & -0.529 & 0.656 & 0.896 \\
\hline COC 7 & Company H\&S Policy & -0.484 & 0.702 & 0.893 \\
\hline COC 6 & Health and safety inspection & -0.464 & 0.702 & 0.893 \\
\hline
\end{tabular}

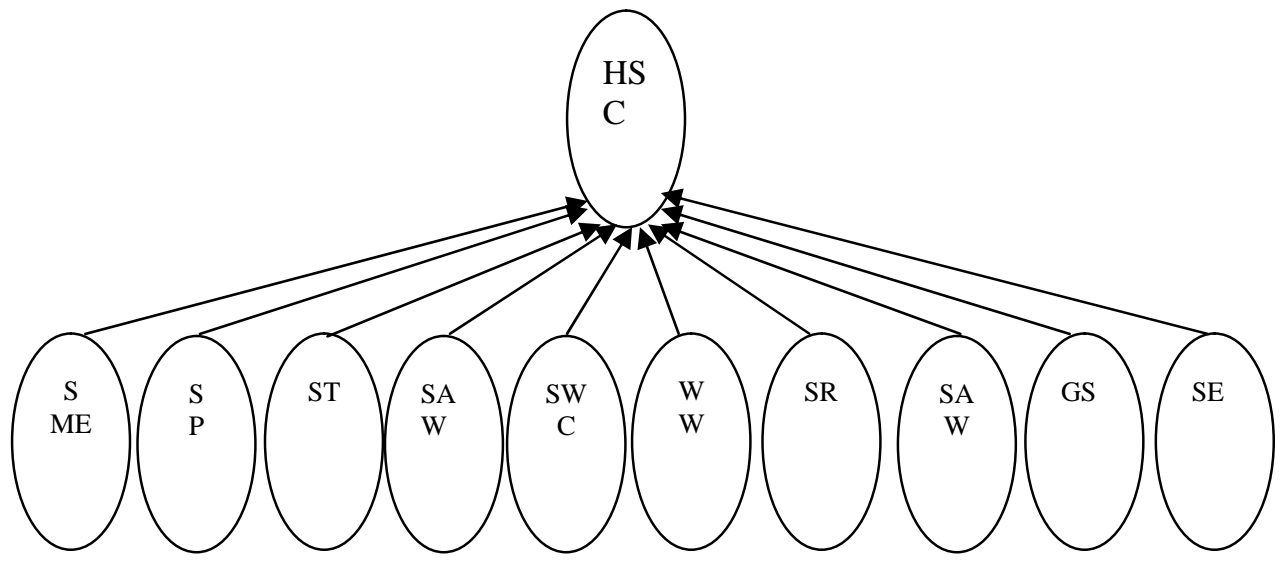

Figure 2: Conceptual health and safety (H\&S) compliance model (Model 2.0)

\title{
8. Measurement Components of the Revised Health and Safety Compliance Model
}

This section gives detail information on the number of latent constructs or variables for each of the factors for the revised model for H\&S compliance for the Ghanaian construction industry. Figure 2 shows that Safety of Materials and Equipment (SME) and Government Support (GS) have five latent constructs or variables each. While Safety Precautions (SP), Safety Training (ST), Workers Welfare (WW), Safe Acts of Workers (SAW), Safe Environment (SE) have four latent constructs or variables each. Contractors' Organisational Culture (COC) has six latent constructs or variables and Safety Precautions (SP) has three latent constructs or variables.

\section{Conclusion}

The purpose of the paper was to present the revised health and safety (H\&S) compliance model for the construction industry based on a developed theoretical six factor model. Twelve factor model was obtained from the theoretical six factor model after conducting EFA. Two factors were dropped due to their weakness in predicting H\&S. Finally, the conceptual health and safety compliance model with ten factors was obtained. Measuring health and safety compliance is a complex construct, therefore, the ten factor model should be applied together accordingly in order to minimize accident. Further research should be conducted using CFA, followed by SEM together with EQations (EQS) version 6.2 software to investigate the measurement model adequacy and structural model goodness-of-fit.

\author{
Nomenclature \\ CFA Confirmatory Factor Analysis \\ EFA Exploratory Factor Analysis \\ EQS EQations \\ H\&S Health and Safety \\ ILO International Labour Organization \\ OHS Occupatioanl Health and Safety \\ KMO Kaiser-Meyer-Olkin \\ PAF Oblimin Principal Axis Factoring with Oblimin Rotation \\ SEM Structural Equation Modeling
}




\section{References}

Annan, J.S., Addai, E.K. and Tulashie, S.K. 2015. A Call for Action to Improve Occupational Health and Safety in Ghana and a Critical Look at the Existing Legal Requirement and Legislation. Safety and Health at Work. Available from http://www.eshaw.net (Accessed 13 April 2015).

Bentler, P.M. \& Chou, C.P. 1987. Practical issues in structural modeling. Sociological methods and research, Vol.16, No. 1, pp. 78-117.

Bolllen, K.A. 1989. Structural Equations with Latent Variables. New York: John Wileys\& Sons, Inc.

Building a Preventative Safety and Health Culture. 2013. A guide to the Occupational Safety and Health Convention, 1981 (No. 155), its 2002 Protocol and the Promotional Framework for Occupational Safety and Health Convention, 2006 (No. 187).

Dadzie, J. 2013. Perspectives of Consultants on Health and Safety Provisions in the Labour Act: A Study into Theory and Practicals. Engineering Management Research; Published by Canadian Center of Science and Education, Vol. 2 , No. 1.

Farrington, S.M., Gray, B. and Sharp, G.D. 2009. Perceptions of an entrepreneurial career.

Paper presented at the $21^{\text {st }}$ Annual Conference of the South African Institute for Management Sciences, Nelson Mandela Metropolitan University, Summerstrand Hotel, Port Elizabeth, $13^{\text {th }}-16^{\text {th }}$ September.

Field, A. 2005. Discovering Statistics Using SPSS (and Sex, Drugs and Rock 'N 'Roll). 2nd Edition. London: Sage.

Hair, J. F., Black, W. C., Babin, B. J. and Anderson, R. E. 2010. Multivariate Data Analysis. A Global Perspective. $7^{\text {th }}$ Edition, Upper Saddle River: Pearson.

Hair, J.F., Anderson, R.E., Tatham, R.L. and Black, W.C. 1998. Multivariate Data Analysis. 5th Edition. Englewood Cliffs, New Jersey: Prentice Hall.

Harris, M.M. and Schaubroeck, J.1990. Confirmatory modeling in OB/HRM: Technical issues and applications. Journal of management information systems, Vol.16, pp. 337-360.

Kheni, N.A., Dainty, A.R.J., \& Gibb, A.G.F. 2008. Health and safety management in developing countries: a study of construction SMEs in Ghana. Construction Management and Economics, Available from https://dspace.lboro.ac.uk (Accessed10 April 2015), Vol. 26, No. 11.

Kline, R. 2005. Principles and Practices of Structural Equation Modeling. $2^{\text {nd }}$ Edition, The Guilford Press: New York.

Leedy, D.P. and Ormrod, E.J. 2010. Practical Research: Planning and Designing. 9th Edition, Upper Saddle River, New Jersey: Pearson Education.

MacCallum, R.C., Browne, M.W. \& Sugawara, H.M. 1996. Power analysis and determination of sample size for covariance structure modeling. Psychological methods, Vol.1, pp. 130-149.

Mustapha, Z., Aigbavboa, C.O. and Thwala, W.D. 2015.Conceptualized integrated health and safety compliance model for the Ghanaian construction industry. $6^{\text {th }}$ International Conference on Engineering, Project, and Production Management (EPPM2015), 2-4 September, 2015, Gold Cost, Australia. ISBN: 978-1-922216-76-2, pp. 416-425.

Pallant, J. (2007). SPSS Survival Manual: A Step-by-Step Guide to Data Analysis Using SPSS Version 15, 3rd Edition, McGraw Hill.

Puplampu, B.B. and Quartey, S.H. 2012. Key issues on occupational health and safety practices in Ghana. International Journal of Business and Social Science, Available from http://ijbssnet.com. (Accessed 13 April 2015), Vol. 3, No. 19.

Tong, D. 2007. An empirical Study of e-recruitment technology adoption in Malaysia. Assessment of modified technology acceptance model. Multimedia University, Malaysia.

\section{Biographical notes}

Z. Mustapha, is a Ph.D. student in the Department of Construction Management and Quantity Surveying, Faculty of Engineering and the Built Environment, University of Johannesburg, Johannesburg. South Africa.

Received February 2016

Accepted March 2016

Final acceptance in revised form June 2016 